\title{
Placa CON GRAFItI DE ESTÉtiCA MOZÁRABE PROCEDENTE DE las EXCAVACIONES del Teatro Romano de CÁdiz
}

\author{
Plate with graffiti of Mozarabic decoration \\ from the excavations of the Roman Theatre of Cádiz
}

Jerónimo Sánchez Velasco

Universidad de Sevilla

Helena Gimeno Pascual

Centro CIL II - Universidad de Alcalá

Recibido: 09/04/2018

Revisado: 30/04/2018

RESUMEN

Un grafiti hallado en las excavaciones del teatro romano de Cádiz representa un edificio cristiano con una iconografía propia de los manuscritos iluminados mozárabes. Este hecho permite abrir nuevas líneas de investigación en la historia de la ciudad durante la época altomedieval, es decir, entre los siglos VII y XI d.C., momento en el que la ciudad estaría supuestamente abandonada.

Palabras Clave

Grafiti; Mozárabe; Edificio cristiano; Epigrafía.

\section{AbSTRACT}

A graffiti found in the excavations of the Roman theatre of Cádiz represents a Christian building with an image of Mozarabic manuscripts. This fact allows us to open new research lines in the history of the city during the high medieval period, that is, between the seventh and eleventh centuries $\mathrm{AD}$, at which time the city was supposedly abandoned.

\section{KEY WORDS}

Graffiti; Mozarabic iconography; Christian building; Epigraphy.

helena.gimeno@uah.es

jsanchez70@us.es 


\section{INTRODUCCIÓN.}

En el marco del proyecto" "Nueva edición de CIL II: - 1. Inscripciones del extremo occidental del conventus Gaditanus (CIL II ${ }^{2} / 6$ ).- 2. Inscripciones de los municipios antiguos en territorio portugués al este del Guadiana" hemos iniciado una campaña de revisión exhaustiva de los fondos epigráficos del Museo de Cádiz ${ }^{2}$. A partir del estudio de la epigrafía y el espacio epigráfico en el que se inserta pretendemos aumentar el conocimiento sobre Gades y su territorio en la Antigüedad y Tardoantigüedad.

Ya en sus inicios el trabajo nos ha sorprendido con singulares materiales. Entre las numerosas placas de mármol, nos llamó la atención la que aquí presentamos: tiene inciso un grafito extraordinario -aunque no epigráfico- prueba evidente de la continuidad del hábitat en Gades en época tardoantigua de la que apenas conocíamos cuatro testimonios epigráficos; a ellos hay que sumar ahora la reciente inscripción recuperada por la Guardia Civil hallada en el yacimiento urbano de la Casa del Obispo ${ }^{4}$ y cuya foto, publicada en el diario ABC de Sevilla de 5 de marzo de $2018^{5}$, nos permite saber que el difunto, Florianus, fue probablemente un $\mathrm{cl}(\mathrm{ericu}) \mathrm{s}^{6}$ que vivió veintitrés años y murió el tercer día de las nonas de abril de

\section{MINEICO (FFI 2016-77528-P)}

2 Queremos agradecer vivamente la inestimable ayuda de Juan Alonso de la Sierra y de Dolores López de la Orden, director y técnica conservadora del Museo siempre dispuestos a ayudarnos de la forma más eficaz posible.

3 La inscripción de Vigilia, del siglo sexto, que según afirman Sánchez (1995) y el inventario ( $n^{0}$ 60) del Museo de Cádiz se encontró en Punta de la Vaca (hoy barrio de San Severiano); una funeraria (ICERV 138), perdida, cuyo texto parece bastante temprano como sugiere Salvador Ventura (1998, 43 n. 44); un fragmento con parte de la indicación de la datación (López de la Orden y Ruíz Castellanos, 1995 n ${ }^{0}$ 28; AE 1995, 790; HEp 6, 1996, 279); un último fragmento hallado en el yacimiento de la Casa del Obispo, fechado en el siglo VII, por el que se sugiere, con cautela, la existencia en Cádiz de edificios funerarios como martyria o basílicas funerarias (cf. Bernal, Lagóstena 2010, 419, 436 y el acertado comentario de I.Velázquez en HEp 19, 2010 [2013], nº 109 ).

4 Con esta ya son dos los testimonios del siglo VII hallados en este yacimiento urbano (véase nota anterior).

5 http://www.abc.es/cultura/abci-guardia-civil-intervienetesoro-arqueologico-investigar-venta-ilegal-cadiz201803011229_noticia.html.

6 Clericus abreviado CLS, como aquí, solo lo hemos encontrado en una inscripción asturiana (IHC 479 La Braña Luarca; Oviedo) a todas luces posterior. la era 708 es decir el año $670^{7}$. Lo importante de esta inscripción es que sabemos que la presencia de un clericus supone la existencia de una comunidad religiosa con la entidad suficiente para requerir una organización. No sabemos si en este caso, los veintitrés años se refieren a su vida sacerdotal como ocurre probablemente en la inscripción de otro clericus de Mértola (Dias y Gaspar 2016, nº 49) ${ }^{8}$-y como nosotros también preferimos entender- sin descartar que pueda ser su edad biológica.

Como decíamos, a estos testimonios epigráficos viene a sumarse la pieza que presentamos aquí y que, como el clericus parece indicar que en Gades perviven comunidades cristianas en la tardoantigüedad.

\section{Gades DURANTE la AntigüEdad TARdía.}

Lamentablemente, es muy poco lo que sabemos de la articulación y desarrollo de la Gades romana. El registro arqueológico poco o nada ha podido aportar sobre la transformación de la vieja ciudad fenicio-púnica en otra de características romanas, tal y como dicen las fuentes que debió ocurrir por el impulso de Balbo el Menor, amigo personal de César y de Augusto, cuyos esfuerzos debieron materializarse en un importante programa de construcción, centrado en la isla mayor, Kotinoussa.

En esta isla, ubicada entre la actuales zonas de La Caleta y la plaza de San Juan de Dios, se han llevado a cabo bastantes excavaciones, pero los resultados han sido tan limitados que resulta imposible articular una mínima teoría sobre la evolución urbana de la ciudad. De hecho, el teatro romano es el único edificio púbico que se conoce de la ciudad altoimperial. Esta sufre, según los datos disponibles, un fuerte retroceso a partir del siglo III d.C., acentuado durante los siglos IV y V d.C., coincidiendo (aparentemente) con el descenso del comercio de productos relacionados con las salazones de pescado. Según recientes teorías, es posible que el puerto siguiera activo, a pesar de la decadencia generalizada de la ciudad ${ }^{9}$. Este es el motivo por el cual la continuidad habitacional de la ciudad se podría prolongar hasta el siglo VII

7 A partir de la foto el texto dice: quiescet / Florianus / cl(ericu)s vixit /an(no)s XXIII et / pausavit / in pace d(ie) III / n(ona)s ap(rilis) e(ra) DCCVIII

8 Adulteus / cle[ri]cus v(ixi)t / an(nos) X r(equie) $v(i) t /$ in p(a)c(e) d(ie) III / Ed(us) Ian(uarias) (!) / DCCXVII

9 Hipótesis emitida en Arteaga et al., 2001, 400 y recogida de nuevo en Bernal et al. 2009, 56. 
d.C., según las últimas investigaciones. Lo que sí sabemos es que Gades no fue obispado y en su lugar cobra importancia Asido (Padilla 1990; Padilla, 2008, 241-258), la gran ciudad de la zona en época tardoantigua (Lagóstena, 2011).

Con estos datos, por tanto, es prácticamente imposible aproximarse siquiera a las transformaciones de la ciudad en la tardoantigüedad (Diarte, 2012, 148-149). Si nos centramos en el teatro, los pocos datos arqueológicos con los que contamos fecharían el abandono ya en el siglo II d.C. Por mímesis con otros teatros, se supone que existe un proceso de colmatación y reutilización de estructuras en desuso. Se han hallado monedas del siglo IV, así como ánforas entre el siglo IV y el VII d.C., aunque sin contextos estratigráficos en la mayoría de las ocasiones. Las ánforas documentadas tienen procedencia sudhispánica, africana, oriental y baleárica, es decir, del ámbito de influencia bizantino. No sabemos con seguridad si el teatro se convirtió en un espacio doméstico, comercial o-simplemente- en un vertedero ${ }^{10}$ usado hasta el siglo VII d.C. Habrá que esperar al siglo XI d.C. para que un asentamiento musulmán ocupe la zona con una alcazaba que será reutilizada y profusamente remodelada por Alfonso $\mathrm{X}$.

No se puede articular un discurso histórico de ese hiato temporal de tres siglos que acabamos de describir. Temas históricos de calado, como la cristianización, el alcance real de la presencia bizantina, la conquista islámica o la implantación omeya son retos para la investigación futura (Lagóstena, 1998).

Sin embargo, esta pieza hallada en las excavaciones del teatro romano nos permite albergar esperanzas a la hora de ir descifrando este sombrío panorama (Corzo y García, 2015).

\section{UNA PIEZA EXCEPCIONAL.}

La pieza tiene el número de registro $25.645 \mathrm{del}$ Museo de Cádiz (Fig. 1). Es una placa de mármol blanco con vetas grises. En su cara mejor pulimentada se conserva parte de un grafiti. La otra cara tiene signos de haber sido pulimentada también, aunque su conservación es peor. Según la ficha del Catálogo

10 Los teatros, por su estructura, son lugares ideales para ser usados como vertederos urbanos (Dupré y Remolà, 2000; Remolà y Acero, 2011). En la Bética, el proceso de transformación en vertedero de un teatro ha sido estudiado específicamente en Córdoba (Sánchez Velasco, 1999; Sánchez Velasco, 2002; Sánchez Velasco, 2011, 134-135).
Sistemático del museo, realizada en noviembre de 2002, la pieza procede de las excavaciones del teatro romano ${ }^{11}$. No se especifica nada más, salvo que se trata de la pieza número 13 de la bolsa 23.549 correspondiente a dichas excavaciones. Por consiguiente, no tenemos información sobre el contexto arqueológico o estratigráfico en el que apareció la pieza. Tampoco sabemos en qué año fue hallada. Así pues, nuestra única referencia segura es que apareció en las excavaciones del teatro anteriores a 2002.

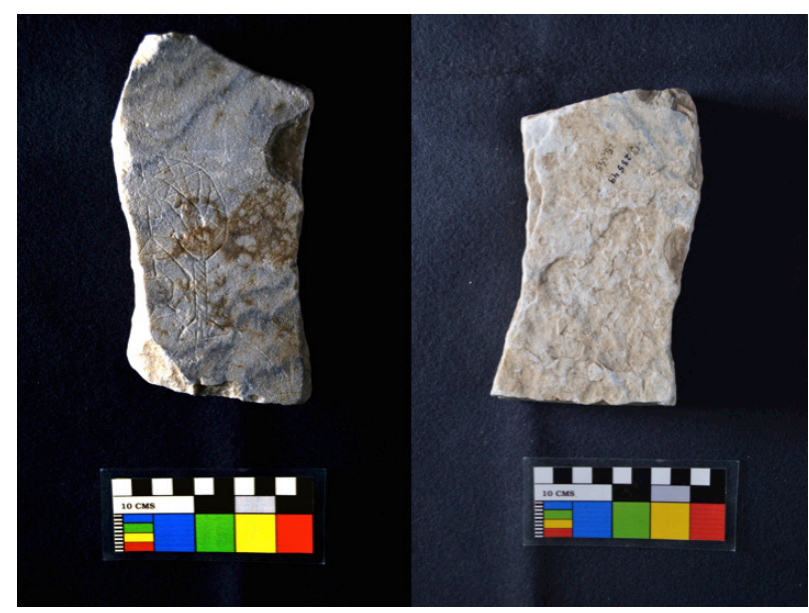

Fig. 1. Placa, anverso y reverso (Fot. R. Balbín).

Sus dimensiones son pequeñas, de 16 × 8 '5 x $355 / 4 \mathrm{~cm}$. El grafito ocupa gran parte de la cara pulimentada, con unas dimensiones de 11 x $55 \mathrm{~cm}$. El trazo de la incisión es fino y superficial, pero nada errático ni improvisado, lo que denota que el autor ha reflejado lo que pretendía sin rapidez. De hecho, en la parte inferior derecha de la pieza aparece el arranque inconcluso de un arco, que ha sido desechado.

En el grabado aparece representado (Fig. 2) un arco ligeramente ultrasemicircular, con un desarrollo algo mayor que los arcos de medio punto, pero llevado a la práctica de forma muy tenue. El arco está formado por dos arquivoltas, la exterior de $1 \mathrm{~cm}$ de grosor, aparece decorada con un motivo reticulado; la arquivolta interior, de 0’5 cm de grosor, aparece a modo de festoneado del arco decorada con palmetas

11 En este punto es necesario recordar que el Teatro Romano de Cádiz y la zona de Casa del Obispo, donde hemos señalado anteriormente que aparecen dos importantes testimonios epigráficos del siglo VII d.C. apenas se distancian $200 \mathrm{~m}$. 
geometrizadas, que en ocasiones parecen triángulos. El arco asienta sobre un capitel, de mayor tamaño que el propio arco, lo que hace que sobresalga por el intradós. Está someramente decorado con una línea central que lo secciona en dos y algún trazo horizontal poco definido.

El capitel está sostenido por un fuste de estrías helicoidales (2'5 x 0’5 cm), extraordinariamente delgado en comparación con el resto de elementos que hemos definido hasta ahora, y se apoya en una basa que imita la forma del capitel hasta el punto de que parece que se le ha dado la vuelta a uno de estos elementos para sustentar el fuste. La rotura del soporte no nos permite saber cómo se completa la representación, pero lo más lógico es que en el lado izquierdo estuviera la parte derecha de la imagen.

Este arco sobre columnas que hemos descrito sirve de marco para una representación arquitectónica muy singular: un trazo vertical mínimo, a modo de muro de carga, sustenta un tejado de dos

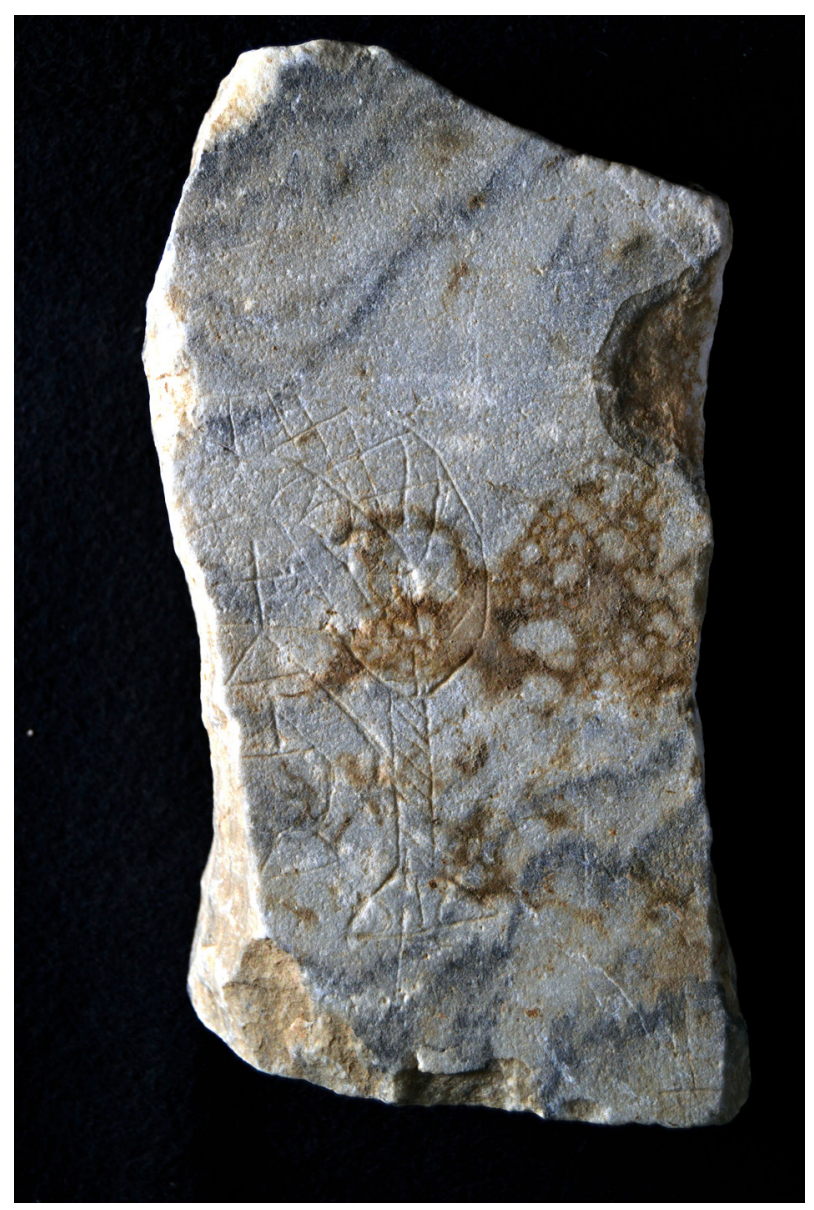

Fig. 2. Detalle del grafiti (Fot. R. Balbín). aguas que aparece coronado con una cruz apocalíptica, con Ro en el vástago vertical de la cruz y unas esquematizadas Alfa y Omega (Fig. 3) en el vástago horizontal; bajo el tejado aparece un tirante de la armadura de madera del que pende, por tres extremos, un recipiente globular con pie troncocónico.

La imagen es muy explícita. Por un lado, se trata de un marco arquitectónico en forma de arco triunfal, típico de la iluminación de los beatos mozárabes y de algunos libros iluminados de época altomedieval. Muchas de las escenas más destacadas de este tipo de documentos aparecen enmarcadas en estructuras arquitectónicas como estas, donde el arco cobra protagonismo como elemento definitorio de la importancia de un contenido. Este recurso no es nuevo. Desde época bajoimperial encontramos la delimitación de contenidos destacados bajo arcos, como escenas bíblicas en sarcófagos o dípticos consulares. Incluso en época paleoislámica, la conformación del mihrab como nicho con arco

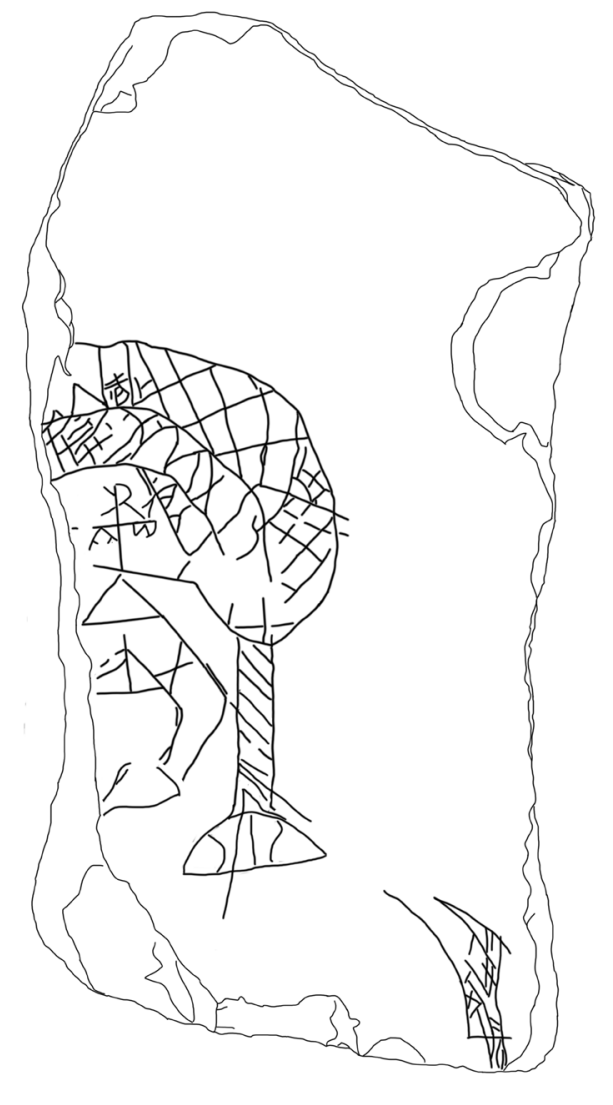

Fig. 3. Dibujo de la pieza con el grafiti (R. Balbín). 
(en este caso con venera) tomará como referente estos modelos clásicos (Sánchez Velasco, 2006, 183195) para la creación del elemento arquitectónico más emblemático de las mezquitas. De hecho, se acuñarán una serie de monedas, las tipo "mihrab" donde la representación es un nicho con venera que enmarca el símbolo del profeta, su lanza.

La distribución del arco en dos arquivoltas con decoración separada es poco frecuente en los manuscritos iluminados altomedievales si lo comparamos con la representación de arcos con un simple trazo o banda, pero esta composición existe, y es usada con relativa frecuencia, como en el arco que enmarca la visión de Daniel en el Beato de Liébana ${ }^{12}$ o en los arcos representados en la apertura del Quinto Sello (Cid Priego, 1984) en el Beato de San Millán de la Cogolla ${ }^{13}$. A ello habría que añadir que el tipo de arco contiene motivos decorativos que ya han sido detectados en otros grafitis altomedievales. Es el caso de la decoración triangular de la arquivolta interior, muy similar a la hallada en grafitis que reflejan arquitecturas en Medina Azahara (Barrera Maturana, 2008).

Más complicada es la interpretación del contenido que se pretende resaltar, y cuya importancia queda de manifiesto por el uso del arco. El simbolismo cristiano es innegable, con la presencia de una cruz apocalíptica como remate de un tejado a dos aguas. Pero el tejado parece como suspendido en el aire, con un mínimo apoyo, esto es, un trozo de muro apenas insinuado con un diminuto trazo vertical. $\mathrm{Y}$ es que las representaciones de iglesias durante el primer milenio tienen, como característica singular, el protagonismo de los tejados rematados con cruces. La imagen del edificio destinado al culto es uno de los temas más frecuentes en la iconografía cristiana arquitectónica, ya sea en mosaico, en relieve, pintura o miniaturas. Así, es recurrente en la musivaria bizantina la aparición de imágenes de iglesias en mosaicos cuya característica principal es la representación del techo de un edificio rematado con una o varias cruces (Galtier, 2001, 267-334): mosaico MNE 613 del Louvre; mosaico de la bóveda de la basílica de Parenzo, donde aparece el obispo Eufrasio donando una iglesia; o Santa Agnese de Roma, con su mosaico en la bóveda del ábside en la que aparece el Papa Honorio I como oferente de la propia basílica. Los ejemplos son numerosos

12 Fechado en el siglo X, MS 11695, fol, 243v

13 Data del siglo X, Biblioteca Nacional, fol. 73 también en los manuscritos iluminados: en el Beato de Liébana aparece representada una iglesia como un enorme tejado (Biblioteca Nacional, fol.176v); el scriptorium que aparece representado en el Beato de Tábara, igualmente, destaca las techumbres tanto en la torre como en las salas aledañas; las iglesias de los concilios toledanos igualmente quedan caracterizadas por amplias techumbres, como en el caso del Códice Albeldense (fol. 142). La forma que tienen en este códice de representar tanto tiendas como altares portátiles nos lleva a desechar la idea de que en el grabado gaditano se trate de reflejar este tipo de estructuras temporales. Como veremos, el siguiente elemento incide en la idea de que lo que se está mostrando es un lugar sagrado de cierta entidad.

El objeto que pende del tirante de la armadura de madera del tejado representado es, con diferencia, la parte más compleja de analizar. Ocupa un lugar central, y su tamaño -claramente simbólico- es desproporcionadamente grande respecto al edifico que lo cobija. Su forma, de cuerpo globular y soporte troncocónico, puede asimilarse a dos tipos de utensilios comunes en las iglesias, y que se colocaban normalmente pendiendo del techo: lámparas e incensarios.

En el primer caso, el uso de lámparas colgantes de esta forma genérica (no se puede hablar de tipología) cubre un amplio espectro temporal. Así, en una píxide de marfil conservada en el Museum of Arts de Nueva York aparece representado el tegurium rotondum de la Anástasis de Jerusalén, un edículo provisto de columnas torsas y cúpula del que pende una lámpara de estas características. Fechado en el siglo VI d.C., sigue la iconografía que representa el tegurium rotondum en las ampollas 9 y 3 del Museo de Monza o en la conservada en el Dumbarton Oaks Collection de Washington: columnas, tejado a dos aguas rematado en cruz y lámparas colgantes (Galtier, 2001, 229-235, ff. 127 y 134). Uno de los ejemplos más lujosos de este tipo de lámparas se encuentra en la colección del Walters Art Museum ${ }^{14}$. Lámparas, formalmente parecidas y hechas en bronce, fueron realizadas para alumbrar las primeras mezquitas, como se puede apreciar en el magnífico ejemplar procedente de Raqqada (Túnez) ${ }^{15}$ y fechado en la primera

14 Un ficha completa de la pieza puede consultarse en http://art.thewalters.org/detail/35353/lamp-2/

15 Se puede consultar la ficha completa en http://www. discoverislamicart.org/database_item.php?id=object;ISL;tn; 
mitad del siglo XI d.C. Sin embargo, este tipo de lámparas altomedievales cuentan, por regla general, con un borde alto y abierto, que en nuestro grabado no existe.

Los cuerpos globulares de base cónica son más frecuentes en incensarios. A lo largo del siglo VIII d.C. existen incensarios bizantinos globulares que tienen una forma casi idéntica al del grafiti, como el que se conserva - también- en el Walters Art Museum procedente de Siria ${ }^{16}$. Este tipo de incensarios, muy simples, pueden estar abiertos o tapados. El modelo tiene bastante éxito, hasta el punto de que en época almorávide aún se realizan cazoletas de incensario idénticas, como la que se conserva en el Museo de la Alhambra (Fernández Puertas, 1976) ${ }^{17}$, aunque en este caso tiene una tapadera calada.

En resumen, los datos aquí expuestos $-y$ ante la falta de referencias estratigráficas- nos llevan a considerar este grabado como una realización de época mozárabe, donde se representa una iglesia cristiana (o parte de ella) de singular importancia, y cuya característica más destacable es un elemento litúrgico vinculado directamente al culto: una lámpara $\mathrm{o}$, más probablemente, un incensario. Todo ello, enmarcado por un arco, con claras reminiscencias en las representaciones de los manuscritos iluminados de la época.

Hasta ahora, los grafitis tardoantiguos o altomedievales no han recibido mucha atención en la Península Ibérica. Tal vez unos de los más estudiados (Jimeno, 2015b, 234, n.5) sean los hallados en la iglesia de Santiago de Peñalba (León). Este caso es especialmente interesante por lo complejo, debido a la diacronía de los grafitis (realizados a lo largo de varios siglos) y a su localización, en muchos casos a una altura que resulta necesario contar con un soporte de considerables dimensiones. Para estos grafitis se ha supuesto un tipo de actuación espontánea, poco preparada, destacando sus similitudes con los grabados de las cuevas artificiales del valle medio del Esla (Jimeno, 2015a), posiblemente eremíticas, aunque esta funcionalidad es sólo una hipótesis

\section{Mus01;15; es\&pageD $=\mathrm{N} \& \mathrm{cp}$}

16 Este magnífico ejemplar con escenas figuradas aparece descrito en la siguiente web http://art.thewalters.org/ detail/27283/censer-with-scenes-from-the-life-of-christ/

17 Se puede consultar online un reciente estudio de este incensario y sus relaciones con el románico hispano en http://www.alhambra-patronato.es/elblogdelmuseo/index. php/romanico-incensario/ de trabajo. De hecho, las investigaciones recientes ven con cierto recelo la relación de estos grabados con los manuscritos iluminados, considerando que "deben ser considerados como un reflejo espontáneo de la vida de los moradores y visitantes de este templo" (Jimeno, 2015b, 259). Aunque algunas representaciones figurativas pueden hallarse en relieves pétreos ${ }^{18}$, como es el caso de un felino (Jimeno, 2015b, fig. 8), otras tienen una estética claramente vinculada a la iluminación de libros, como el supuesto presbítero (Jimeno, 2015b, fig. 9), que aparece acompañado de una explicación escrita. A ello habría que añadir, en estas fechas tan tardías y en ámbitos profundamente ruralizados, que la capacidad de escribir, era algo al alcance de una reducida minoría, incluso entre la aristocracia. Las dudas que puedan existir a este respecto para los grafitis leoneses no son aplicables al caso del grafiti gaditano que nos ocupa, porque como hemos podido ver, tanto la composición como el tema están íntimamente relacionados con el acervo de imágenes de la iluminación de libros en época mozárabe.

A modo de conclusión, podemos decir que nos encontramos ante una placa que quizá sirvió de pavimento o zócalo de muro de algún edificio, a tenor del pulimentado de la cara grabada y del estado de la cara posterior. Su superficie fue incisa premeditadamente y con un alto grado de preparación, a juzgar por el arco inconcluso que se encuentra en la parte inferior derecha de la pieza. Quien realizó el grafiti estaba muy familiarizado con los recursos iconográficos usados en los manuscritos iluminados de época mozárabe, y era capaz de reproducirlos de manera explícita. Por consiguiente, pensamos que es factible mantener la hipótesis de que este grafiti ha sido realizado por un monje o por alguna persona -no necesariamente religiosa - acostumbrada a ver este tipo de obras artísticas. Su intención fue reproducir un lugar especialmente sagrado, una iglesia o santuario lo suficientemente genuino como para ser reconocido con la simple representación - a tamaño simbólicode una lámpara o incensario.

18 Una prueba de ello es el relieve altomedieval de Chelas (Portugal) con sus felinos, aunque la relación estética con el mundo de las miniaturas es evidente. 
4. Nuevas Perspectivas para la ciudad de Gades durante la Alta Edad Media.

A pesar de las limitaciones que tiene toda pieza descontextualizada o con una representación tan mínima, creemos que supone un dato muy importante a tener en cuenta a la hora de acometer la tan necesaria actualización de los datos referentes a la Tardoantigüedad y la Alta Edad Media en la ciudad de Cádiz. La revisión de antiguas excavaciones y el estudio de las piezas conservadas en los museos y colecciones museográficas son una fuente de información de primer orden.

Este caso que nos ocupa reactiva todas las cuestiones que desde hace años planean sobre la historia de la ciudad de Cádiz entre el siglo VII y el XI d.C. La realización de este tipo de grafitis podría estar indicando la existencia de una comunidad de monjes asentada en la ciudad en época mozárabe. Si fue creada ex novo o si pervive desde la tardoantigüedad no podemos saberlo aún pero la inscripción del clericus Florianus (vid. supra) apuntaría en esta última dirección. La existencia de esta posible comunidad monacal (que, insistimos, barajamos a modo de hipótesis de trabajo) estaría íntimamente relacionada con la pervivencia de Cádiz como fondeadero o punto de abastecimiento en las rutas marítimas que unían el Mediterráneo y el Atlántico. Recientes investigaciones pluridisciplinares (Campos y Bermejo, 2017) han puesto de manifiesto la vitalidad de estas rutas a lo largo de la Antigüedad Tardía, conectando tanto con puertos oceánicos (Huelva, Faro) como interiores (Sevilla, Mértola). La evidente hegemonía de la Asido tardoantigua sobre el territorio occidental del antiguo conuentus Gaditanus no significa que las rutas comerciales en la zona desaparecieran. Los hallazgos de cerámicas del ámbito económico y político bizantino en Vigo (Fernández Fernández, 2014) sólo ratifican la evidencia de la continuidad del importante circuito comercial atlántico usado en época romana (Morillo et al., 2016). Y Cádiz debió seguir siendo un lugar apto para fondear. La presencia de una posible comunidad religiosa -más o menos importante- podría deberse, de hecho, a la existencia, uso y mantenimiento de esta ruta marítima y sus fondeaderos. El caso del monasterio hallado en la isla de Cabrera (Riera, 2014) es bien conocido y su existencia se debe a la presencia de rutas comerciales en las que esta isla cumplió una función básica como fondeadero. Recientemente, se ha puesto de manifiesto la vinculación entre los monasterios y el control de puertos (Sánchez Velasco, 2018, 204-207) y rutas terrestres en la Bética Occidental gracias a éstos (Sánchez Velasco, 2018, 312-313) ${ }^{19}$, cuestión que ha sido estudiada ya en el resto de Europa (Basso y Zanini, 2016), donde sabemos que las fundaciones monacales son promovidas por los diferentes obispados con fines económicos y de control del territorio (Corsi, 2016, 53). Tal vez pudo ser este el caso de Cádiz y su relación con Asido durante la Antigüedad Tardía y la Alta Edad Media.

En cualquier caso, estamos esperanzados en que la continuidad de nuestras investigaciones arrojen suficiente luz para aquilatar estos primeros resultados, tan prometedores, que abren nuevas vías de estudio y nuevas perspectivas para el conocimiento de Cádiz en su etapa más desconocida.

\section{Bibliografía}

Arteaga, O. Kölling, A., Kölling, M., Roos, A.M., Schultz, H. y Schultz, H.D. (2001) "Puerto de Gadir. Investigación geoarqueológica en el casco antiguo de Cádiz”, Revista Atlántico-Mediterránea de Prehistoria y Arqueología Social, 4, 345-415.

Barrera Maturana, J.I. (2008), "Nuevos graffiti en Madīnat al-Zahrā"” Cuadernos de Madinat al-Zahra 6, 53-92.

Basso, P., y E. Zanini, (2016), Statio Amoena: Sostare e viverelungo le strade romane, Archeopress.

Bernal, D., Arévalo, A., Carranza, T. y Montero, J. (2009), "El teatro romano de Gades. Una propuesta interdisciplinar para 2012)", Anales de Arqueología Cordobesa, 20, 155-174.

Bernal Casasola, D. y Lagóstena Gutiérrez, J, (2010), "Muriendo en Gades en la Antigüedad Tardía”, Las necrópolis de Cádiz. Apuntes de Arqueología Gaditana en homenaje a F. Sibón Olano (A. M ${ }^{a}$. Niveau de Villedary y Mariñas, V. Gómez Fernández, coords.), Cádiz, 407-404.

Campos, J. y Bermejo, J. -Eds.- (2017), Los Puertos Atlánticos Béticos y Lusitanos y su relación comercial con el Mediterráneo, Roma.

Cid Priego, C. (1985), "La miniatura de la apertura del Quinto Sello en el Beato de Girona: estudio comparativo de la serie de los Códices”, Annals

19 Las hipótesis sobre la relación establecida entre monasterios, vías, actividades económicas y control del territorio para la Bética Occidental fueron establecidas en Sánchez Velasco, 2012. 
de l'Institut d'Estudis Gironins, 27, 37-86.

Corsi, C., (2016), 'Street Villages and Road Stations in Italy between Late Antiquity and the Early Middle Ages', Statio Amoena: Sostare e viverelungo le strade romane (P. Basso e E. Zanini, Eds.), Archeopress, 53-67.

Corzo Sánchez, R. y García García, M.A. (2015), "Una placa marmórea decorada con motivo cristiano en el teatro romano de Cádiz”, Laboratorio de Arte, 27, 541-547.

Diarte Blasco, P. (2012), La configuración urbana de la Hispania tardoantigua. Transformaciones y pervivencias de los espacios públicos romanos (s. III-VI d.C.), BAR Inter. Series, Oxford.

Dias, M. M. A., y Gaspar, C. I. S. (2006), Catálogo Das Inscrições Paleocristãs Do Território Português, Lisboa.

Dupré Raventós, X. y Remolà Vallverdú, J.A. (2000), Sordes urbis. La eliminación de residuos en la ciudad romana, Roma.

Fernández Fernández, A.,(2014), El comercio tardoantiguo (ss. IV-VI) en el noroeste peninsular a través del registro cerámico de la Ría de Vigo, Archeopress.

Fernández Puertas, A. (1976), "Incensario de época Almorávide”, Miscelánea de Estudios Árabes y Hebraicos, 25, 115-122.

Galtier Martí, F. (2001), La iconografía arquitectónica en el arte cristiano del primer milenio. Perspectiva y convención; sueño y realidad, Zaragoza.

González Fernández, J. (1982), Inscripciones romanas de la provincia de Cádiz, Cádiz.

Jimeno Guerra, V. (2015a), Arquitectura excavada y aprovechamiento de cuevas naturales en la provincia de León, Tesis Doctoral Inédita.

Jimeno Guerra, V. (2015b) "Un patrimonio oculto y recuperado. Los graffiti de la iglesia de Santiago de Peñalba (Peñalba de Santiago, León)", Medievalismo, 25, 233-259.

Lagóstena Barrios, L.G. (1998), "La bahía gaditana en la Antigüedad Tardía”, Homenaje al Profesor Carlos Posac Mon, Ceuta, 265-278.

Lagóstena Barrios, L.G. (2011), “Asido Caesarina: la antigüedad romana de Medina Sidonia”,Historia de Medina Sidonia: De los orígenes a la época medieval. vol. 1 (D. Caro Candela, coord.), Cádiz, 116-191.

López De La Orden, D. y Ruiz Castellanos, A. (1995), Nuevas inscripciones latinas del Mu- seo de Cádiz, Cádiz.

Morillo, A., Fernández-Ochoa, M.C. y Salido, J. (2016) "Hispania and the Atlantic Route in Roman Times: new Approaches to Ports and Trade: Hispania and the atlantic route in Roman times”, Oxford Journal of Archaeology ,35 (3), 267-284.

Padilla Monje, A. (1990), "La transferencia de poder de Gades a Asido. Su estudio a través de la perspectiva social”, Habis, 21, 241-258.

Padilla Monje, A. (2008), “Aproximación a la ordenación territorial de la Bahía de Cádiz durante el Imperio Romano Tardío”, Revista Atlántico-Mediterránea de Prehistoria y Arqueología Social, 10, 353-374.

Remolà Vallverdú, J.A. y Acero Pérez, J. (2011), La gestión de los residuos urbanos en Hispania. Xavier Dupré Raventós (1956-2006). In Memoriam. Madrid.

Riera Rullán, M. (coord. 2014), El Monestir de Cabrera. Segles V-VIII d.C. Mallorca.

Sánchez, J.M. (1995), "La primera inscripción cristiana de la ciuda de Cádiz", IV Reunió d'Arqueologia Cristiana Hispánica (Lisboa 1992), Barcelona, 183-184.

Salvador Ventura, F. (1998), Prosopografía de Hispania meridional, Granada.

Sánchez Velasco, J. (1999), "El acceso norte al teatro romano de Córdoba: secuencia estratigráfica y estudio de materiales”, Anales de Arqueología Cordobesa, 10, 115-159.

Sánchez Velasco, J. (2002), "Evidencias arqueológicas de un taller de mosaicos en Córdoba”, Empuries, 52, 2000, 289-306.

Sánchez Velasco, J., (2006), Elementos arquitectónicos de época visigoda en el Museo Arqueológico de Córdoba: Arquitectura y Urbanismo en la Córdoba Visigoda (Córdoba), Córdoba.

Sánchez Velasco, J. (2011), "Corduba”, La Gestión de los Residuos Urbanos en la Hispania Romana (J. A. Remolá y J. Acero, Eds.), Madrid, 123-143.

Sánchez Velasco, J. (2012), Arquitectura y Poder en la Betica Occidental entre los siglos IV y VIII d. C. La Cristianización de las Ciudades y del Territorio, Tesis Doctoral Inédita.

Sánchez Velasco, J. (2018), The Christianization of Western Baetica Architecture, Power, and Religion in a Late Antique Landscape, Amsterdam University Press. 